\title{
ESTUDIO DEL HÉROE DESGONOGIDO: SEARCHING FOR SUGAR MAN
}

\author{
Raúl García Sáenz de Urturi \\ Universidad de Alicante
}

\section{INTRODUCCIÓN}

El documental Searching for Sugar Man de Malik Bendjelloul se ha convertido en uno de los productos audiovisuales más aclamados del 2013, y en uno de los documentales musicales más reconocidos en los últimos años, alcanzando una difusión para el gran público que parecía exclusiva de los recientes trabajos de Martin Scorsese sobre músicos como Bob Dylan - George Harrison. Este estudio se propone explorar la particularidad del enfoque de este documental sobre la figura del desconocido compositor y cantante Sixto Rodríguez. A partir del análisis de la estructura de la narración de la película y de la dosificación de la información que maneja el director, se pondrá en valor la propuesta que diferencia este documental musical de otros estudios clásicos de la música reciente.

A través de la revisión documental, del análisis comparativo del discurso y de los recursos narrativos utilizados, se diferencia esta obra del estándar habitual gracias a tres pilares fundamentales para su aceptación entre crítica y público: la presencia de un autor maldito, la recompensa final e inesperada para con su obra, y el formato de investigación sobre su trayectoria.

Searching for Sugar Man (2012), el documental del director sueco Malik Bendjelloul sobre la figura del desconocido Sixto Rodríguez, supone uno de los mayores éxitos de crítica y público del género rockumentary de los últimos años. Este género es definido por Matt Stahl como "una forma de documental que se centra en la experiencia subjetiva de una obra particular dentro y fuera de las industrias culturales capitalistas contemporáneas" (citado en Abeillé, 2012: 56). Las obras encuadradas en el rockumentary aumentan cada año en repercusión mediática, de crítica y público. En países como España, iniciativas culturales de la envergadura del In-Edit Festival ${ }^{1}$ de Barcelona potencian este hecho. Según cifras oficiales, en su primera edición, en 2003, este festival internacional especializado en el documental musical contó con treinta y seis sesiones y una asistencia de 1.200 espectadores; y en su penúltima edición, 2012, la programación ascendió a ciento tres sesiones y la asistencia fue

1 Más información: http://www.in-edit.org/webapp/ 
de 31.062 espectadores. Natalia Rueda ha ofrecido algunas razones para el incremento del alcance de los documentales musicales:

El éxito se debe también al registro de reconocidos grupos y artistas que cuentan con un amplio público interesado en conocer sus historias y trayectorias. En este caso, el espectador llega al documental atraído por su protagonista y por la oportunidad de acceder a una suerte de backstage que le permite acercarse a la vida personal del rock star que apenas conoce en tarima (Rueda, 2012: 1173).

Como ejemplos de documentales musicales aclamados por el público en esta última temporada (2012/2013) destacan proyectos como 20 Feet from Stardom (Morgan Neville, 2013), que cuenta con estrellas de la talla de Bruce Springsteen, Sting, Mick Jagger o Stevie Wonder; Big Easy Express (Emmett Malloy, 2012), sobre la gira en tren de los grupos Mumford \& Sons, Old Crow Medicine Show y Edward Sharpe and the Magnetic Zeros. Otros documentales anteriores y representativos de este género han sido Gimme Shelter (1970) o What's Happening! The Beatles in America (1964), de los hermanos Maysles; o los trabajos de Scorsese como montador en Woodstock: 3 Days of Peace \& Music (Michael Wadleigh, 1970) y Elvis on Tour (Robert Abel, Pierre Adidge, 1972) y como director: The Last Waltz (1978), No Direction Home: Bob Dylan (2005), Shine a Light (2008), y George Harrison: Living in the Material World (2011); y documentales como Year of the Horse (Jim Jarmusch, 1997), The Filth and the Fury (Julien Temple, 2001) o When You're Strange (Tom DiCillo, 2009), todos ellos centrados en figuras referentes de la música, con proyección pública a nivel internacional.

En relación con la realización y la recepción de los rockumentales, señala Nogueira que ambos "pasan por una frecuente tensión entre las posiciones perceptivas y afectivas del melómano y el cinéfilo" (citado en Rueda, 2012: 1179). Sin embargo, en Searching for Sugarman no se parte de esta tensión, ya que el melómano, en la mayoría de los casos, no conoce la obra de Sixto Rodríguez, ni siquiera la existencia del mismo.

Por su parte, la propuesta documental de Malik Bendjelloul puede considerarse, en lo que respecta a la estructura narrativa y al tratamiento de la búsqueda de Sixto Rodríguez, más cercana a los postulados del cine negro. Este factor, junto con el indudable interés musical e histórico de la figura de Rodríguez y su inverosímil travesía hacia la fama con el reconocimiento público final (propio, en palabras del director, de un arco de resurrección, o de un cuento de hadas), ha hecho de Searching for Sugar Man un rara avis en el mercado del rockumentary contemporáneo, y una pieza de gran atractivo para todo tipo de público, no sólo el especializado o habitual del género.

Bendjelloul escoge para su trabajo la modalidad interactiva, siguiendo la categorización de Nichols, en el que el documental "hace hincapié en las imágenes de testimonio o intercambio verbal y en las imágenes de demostración (imágenes que demuestran la validez, o quizá lo discutible, de lo que afirman los testigos)" (1997: 79), y con un tipo de trama arquetípica, según la propuesta de Abeillé quien lo enmarcaría en la Tragedia, con la característica de una "caída del protagonista y conmoción del mundo en el que habita" (2012: 58). El acierto de Bendjelloul se establece al comenzar con unos personajes que desde el inicio dan por hecha la caída del protagonista y que, sin embargo, a lo largo del documental se definen en la búsqueda e investigación de su rastro en Sudáfrica y USA. 


\section{ANÁLISIS DEL DISCURSO FÍLMICO}

Searching for Sugarman, primera película del director Malik Bendjelloul (Suecia, 1977) describe la investigación de los sudafricanos Stephen Segerman y Craig Bartholomew para descubrir la realidad del mito Sixto Rodríguez, héroe musical de la Sudáfrica de los años setenta del que no se tenía ningún testimonio real.

Partiendo del modelo de análisis fílmico propuesto por Tarín (2006: 42), el documental Searching for Sugar Man se puede organizar en dos partes claramente diferenciadas:

- Una primera pieza del documental, desarrollada en los primeros 49 minutos y en la que se relata la figura de un músico llamado Sixto Rodríguez, que aparece como el objeto de una investigación para descifrar una leyenda, un mito del que apenas se tienen datos reales más allá de dos discos, Cold Fact (1970) y Coming from Reality (1971), que no tuvieron repercusión en USA y que, sin embargo, fueron la banda sonora de los movimientos sociales que surgieron en la Sudáfrica del Apartheid de los años 70.

- La segunda pieza del documental, de 38 minutos, donde se narra la reaparición (casi inverosímil) del autor de estos discos, y la gira de reconocimiento que realiza en Sudáfrica en 1998, un tardío reconocimiento a un músico que había ignorado su fama durante más de veinte años.

Para abordar el presente análisis, denominaremos a estas dos partes "investigación" y "resurrección y recompensa", respectivamente.

\subsection{Primera parte: Investigación}

En Searching for Sugar Man el proceso de investigación comienza con la presentación de dos escenarios principales, Ciudad del Cabo y Detroit. La primera fue la ciudad donde Rodríguez tuvo repercusión pública y en la que se convirtió en un héroe desconocido. La segunda, su ciudad de origen, su hogar, el lugar donde se convirtió en leyenda. Las imágenes 1 y 2 muestran el recurso de fotografía adoptado por Bendjelloul en la elección de la luz para presentar ambas ciudades, resultando esa evidente diferenciación de espacios y tonos propuesta por el director:

(1)

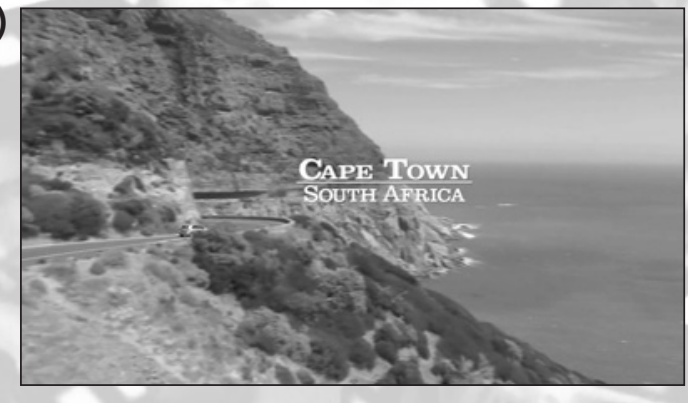

(2)

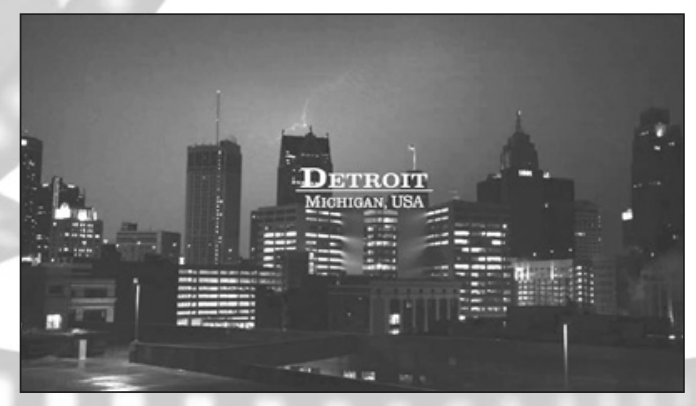

A través de los testimonios de Dennis Coffey y Mike Theodore, sus primeros productores, y de distintos personajes que coincidieron con él, o llegaron a conocer sus discos, se nos dibuja un 
personaje arquetípico: músico maldito, personaje esquivo entre brumas, y poeta callejero maldito de la ciudad de Detroit, ciudad donde nadie sabía muy bien dónde vivía, ni a qué se dedicaba.

Para presentar a esta figura enigmática al espectador, el director se sirve en los primeros minutos de varias de las características del género negro propuestas por Hirsch, y enumeradas por Frago (2008: 274), tales como: el hecho de tener como escenario una gran ciudad americana (imagen 2), la recreación visual de ambientes nocturnos y oscuros (imagen 3), la presencia de coches circulando sobre calles y esquinas vacías (imagen 4), la presencia de la lluvia y las aceras mojadas como motivo recurrente (imagen 5) y el uso del claroscuro y la presencia de sombras marcadas (imagen 6).

(3)

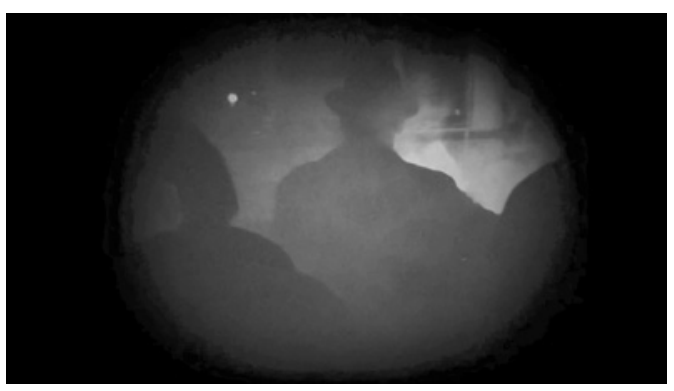

(5)

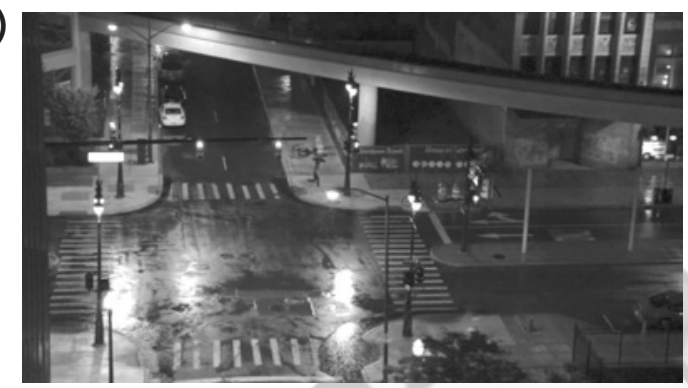

(4)

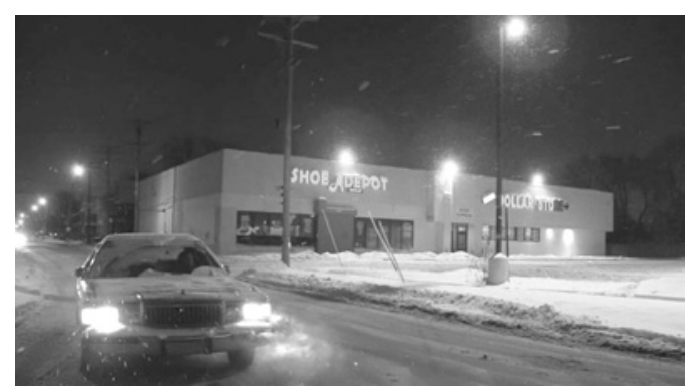

(6)

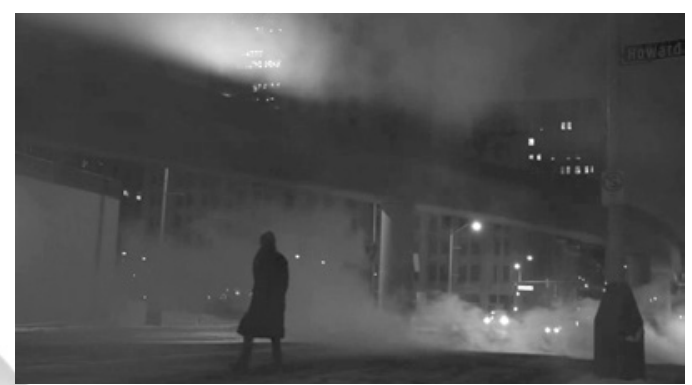

Encontramos también numerosos puntos en común del documental con los rasgos del género negro que propone Noriega, y que enumera Sullà (2010: 20):

a) los personajes estereotipados: Sixto Rodríguez, poeta maldito;

b) las historias dramáticas en la evolución de la trama, donde la muerte o la violencia tienen un protagonismo importante: los rumores sobre el supuesto suicidio del protagonista;

c) los conflictos y la criminalidad determinados por un contexto social: el Detroit marginal de los setenta;

d) los personajes situados al margen de la ley en cuya conducta no siempre coinciden legalidad y moralidad: ¿Es Rodríguez un homeless que escribe canciones antisistema y sobre las drogas?

e) la acción narrada es contemporánea y ocurre preferentemente en espacios urbanos: Detroit y Ciudad del Cabo;

f) la estética visual tiene carácter expresionista: Las recreaciones animadas del Detroit de los setenta responden a este patrón.

Seguidamente, la película nos relata la inexplicada llegada a Sudáfrica de los discos Cold Fact y Coming from Reality, y su encarnación en los ideales de rebeldía de los jóvenes sudafricanos frente al Apartheid. Temas como "The Establishment Blues" o "I wonder" pul- 
saban la conciencia de los jóvenes, convirtiendo a los discos en uno de los imprescindibles en cualquier casa, junto al Abbey Road (1969), de The Beatles, o Bridge Over Troubled Water (1970), de Simon and Garfunkel.

Dos personajes que vivieron aquella revolución musical, Stephen 'Sugar' Segerman y Craig Bartholomew, serán los investigadores que emprendan la búsqueda de información sobre la figura de Sixto Rodríguez, al ratificar que, en aquellos años, no se tenía ningún dato sobre el autor de dos discos tan significativos y vendidos en su país. El primer paso para averiguar datos reveladores será el destino del dinero que producían las numerosas ventas de los discos. Así, tras entrevistar a varios distribuidores del disco en Sudáfrica en los setenta, Bendjelloul nos muestra la entrevista al supuesto destinatario de los royalties: Clarence Avant.

En los primeros momentos, Avant se mostrará emocionado por el recuerdo de Rodríguez ("uno de mis mejores músicos", dirá), pero rápidamente pasará a mostrarse esquivo y agresivo ante las preguntas sobre el destino del dinero, que nunca llegó al autor de los discos, ni en forma de derechos de autor ni en calidad de royalties. Este personaje representa en la película el arquetipo de la sombra, el rival o enemigo de Rodríguez. Encarna, en una sola escena, el lado oscuro de la industria musical que dejó a Sixto Rodríguez sin los millonarios derechos de la venta de sus discos en Sudáfrica. Clarence Avant es, además, el único personaje al que se le ensombrece la cara (de forma literal en la imagen 7, se encara al director y

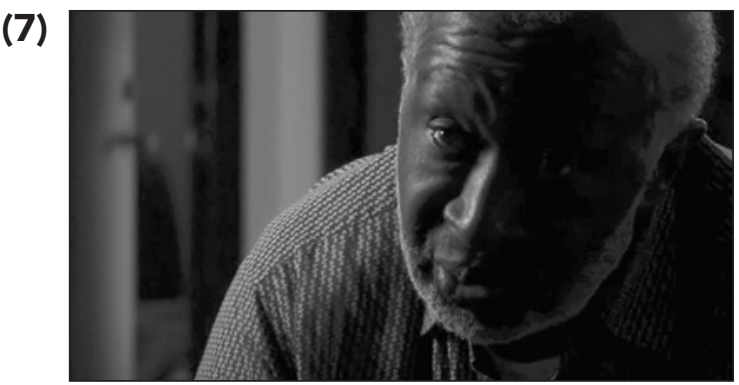
se sale de foco) cuando tratan de preguntarle sobre el inexplicado destino del dinero de las ventas de los discos. Una nueva utilización del claroscuro que mencionaba Hirsch.

Llegados a este punto, y tras seguir a los investigadores hasta varios callejones sin salida, cuando ambos están a punto de abandonar la búsqueda y el espectador se encuentra ante un cierre de la historia sin final feliz, Malik Bendjelloul conduce el documental hacía dos clímax encadenados, que provocarán la catarsis de los investigadores, de Rodríguez, y del propio espectador con ellos. Según Vogler $(1998,239)$, en su análisis del camino del héroe, en la undécima etapa (la resurrección): "El clímax que se pretende provocar en el héroe y en el público es el momento en el que éstos son más conscientes, el momento en el que han alcanzado el punto más alto en la escalera de la conciencia. Se trata, pues, de elevar la conciencia de ambos, héroe y público participante".

Estos dos clímax narrativos corresponden a: en primer lugar, el descubrimiento de uno de los investigadores, Craig Bartholomew, cuando localiza a Mike Theodore, primer productor de Rodríguez, y le confirma que éste continúa vivo en Detroit; en segundo lugar, el mensaje de contacto de una de las hijas de Rodríguez a Stephen Segerman, que culminará con una llamada de madrugada al cantante, y en la que se escucha por primera vez la voz de Sixto Rodríguez, confirmándonos él mismo que sigue vivo.

Las Tecnologías de la Información y la Comunicación (TIC) desempeñan en este punto de la historia un papel muy relevante. La comunicación entre una de las hijas de Rodríguez y los investigadores fue posible gracias a la página web que éstos habían publicado en 1997, haciendo un llamamiento a cualquier persona que pudiera dar información sobre el artista. Esta nueva comunicación mediada por ordenador supuso un avance determinante en la investigación, y una muestra de lo apuntado por Steve Woolgar $(2005,20)$ sobre las consecuencias sociales de las 
nuevas tecnologías y "la idea de que los efectos transformadores de estas tecnologías suponen nuestra transición hacia una sociedad virtual". En efecto, la existencia de aquel espacio digital en Internet supuso un conocimiento y un acercamiento virtual clave en el transcurso de la historia.

Por otra parte, visualmente, Malik Bendjelloul narra el primer clímax, las reacciones de Segerman al saber que Rodríguez continúa vivo, con imágenes de una playa al amanecer (posiblemente Ciudad del Cabo), y la canción "I Think of You" del disco Coming from Reality, una letra y una música nostálgica sobre un amor perdido.

(8)

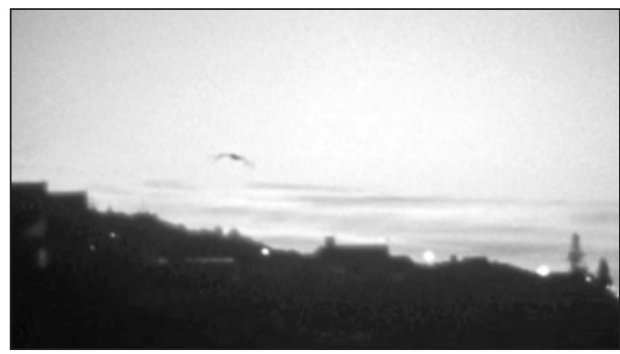

Just a song we shared, I'll hear

Brings memories back when you were here

Of your smile, your easy laughter

Of your kiss, those moments after

I think of you,

and think of you.

Para el segundo clímax, la llamada y la aparición del propio Rodríguez, Bendjelloul selecciona intencionadamente otro amanecer (imagen 9), esta vez en Detroit, mostrándonos los primeros planos de la humilde casa de Rodríguez en la actualidad, y el final instrumental de la canción "Sandrevan Lullaby", también del disco Coming from Reality.

(9)

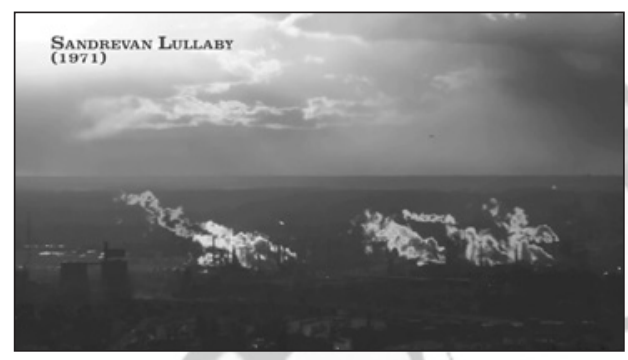

Sea of neon lights, a boxer his shadow fights Soldier tired and sailor broken

Winter's asleep at my window

Así, con los dos escenarios principales alineados bajo la misma luz del amanecer, y una puesta en escena naturalista, en la que Sixto Rodríguez abre la ventana de su casa y mira a la cámara, directamente al espectador, se alcanza la catarsis de esta primera parte del documental.

\subsection{Segunda parte: Resurrección y recompensa}

Searching for Sugar Man da un giro inesperado a partir del descubrimiento de la existencia de Sixto Rodríguez, derribando el mito de su suicidio y de lo esquivo de la fama y el reconocimiento para con su figura. De este modo, los siguientes 38 minutos del documental se transforman en una recompensa, un viaje por el reconocimiento público y la epifanía de un músico que estuvo cerca de no conocer su éxito en otro país, en otro continente, y del que el espectador occidental no tendría noticia si no fuera por esta película.

En esta segunda parte, el documental retoma las pautas clásicas de un modelo interactivo, sin utilizar herramientas de ningún género de ficción, y nos muestra una serie de entrevistas de Sixto Rodríguez, de sus hijas y de compañeros de su trabajo, transmitiendo entre todos esa vida sencilla y austera que vivió como obrero de la construcción en Detroit. 
A través de estas entrevistas, Bendjelloul narra muchas de las cosas que hizo Rodríguez para sobrevivir, presentando sus inquietudes políticas, su aceptación del no-éxito con naturalidad, sus creencias culturales, la historia de su familia, la educación de sus hijas, etc. y, por supuesto, la gira por Sudáfrica de 1998, que le devolvió la fama y el reconocimiento público internacional. Momentos emotivos que nos permiten, como espectadores, asistir a la resurrección de Sixto Rodríguez como ser humano y músico relevante.

Una historia singular que encuentra su realce en la imagen fílmica, Bendjelloul vuelve a jugar con el tipo de luz empleada en esta segunda parte para reforzar el regreso de Sixto Rodríguez, como músico de referencia.

(10)

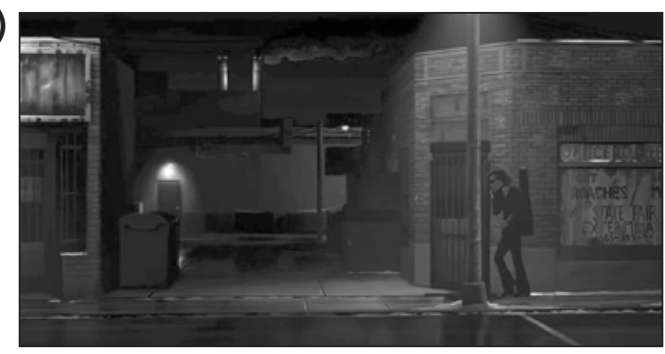

(11)

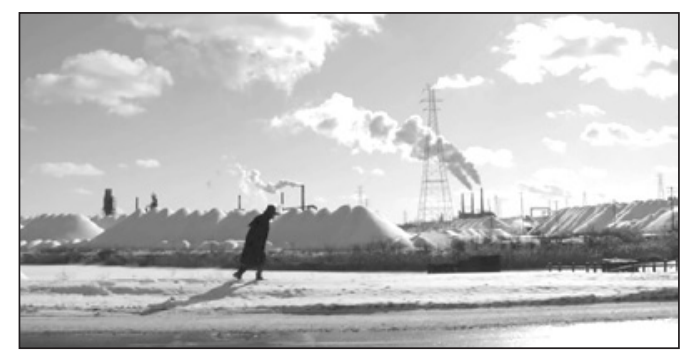

Así, un ejemplo a destacar puede ser esta comparación de la fotografía entre la primera parte del documental (Imagen 10) y la segunda parte (Imagen 11) para representar la trascendencia pública de la figura de Sixto Rodríguez. En la primera imagen Bendjelloul muestra una animación donde se presenta a un Rodríguez callejeando por una ciudad oscura; en la segunda imagen, el Rodríguez real avanza sobre la nieve, en un día soleado de Detroit, en el camino de vuelta a su casa, un lugar sin sombras ni malditismo. Rodríguez vuelve de su camino por el ostracismo, y se encuentra una ciudad luminosa, radiante.

Para reforzar el regreso de Rodríguez a la escena pública como músico de éxito, Bendjelloul se centra en las imágenes del primer concierto de reconocimiento, celebrado el seis de marzo de 1998 en Sudáfrica, para narrar un momento de éxtasis y reencuentro entre Rodríguez y el público que nunca tuvo o llegó a conocer antes. Con el tema "I wonder" se muestra la epifanía de Sixto Rodríguez ante miles de seguidores que siempre lo creyeron muerto y desaparecido. Unas imágenes reafirmadas por el director con las reflexiones del periodista y escritor Rian Malan: "¿No es ese nuestro más ansiado destino? Los sueños de que tu ser, algún día, será reconocido junto con sus talentos, y que serán visibles al mundo... Quiero decir, la mayoría de nosotros se muere sin haber conocido esa magia..."

Searching for Sugar Man llega a su final con una imagen singular, resplandeciente y cargada de valor, en la que podemos ver a un Sixto Rodríguez caminando por las calles de su barrio, con el tema "I'll slip away", de su tercer e inacabado disco, y con la reflexión de que todo ha cambiado a su alrededor, incluida la vida de mucha gente que lo buscó y reconoció. Sin embargo, él sigue siendo el mismo, siempre fiel a sus ideales, buscando su propia felicidad, como marca esta canción que se cierra la película.

And you can keep your symbols of success Then I'll pursue my own happiness And you can keep your clocks and routines Then I'll go mend all my shattered dreams 


\section{Maybe today, yeah \\ I'll slip away"}

\section{CONCLUSIÓN}

Searching for Sugar Man constituye un documental musical atípico, como atípico es el protagonista y la historia que nos narra el director Malik Bendjelloul. Por un lado, narrativamente, estructura su historia con dos partes bien diferenciadas, en las que se aprecia una deuda hacia el género negro en la primera parte como presentación del personaje y de la investigación, y un formato más tradicional, acorde con el rockymentary más interactivo y expositivo, en el fragmento correspondiente a la catarsis. Por otro lado, la trayectoria del protagonista, Sixto Rodríguez, un músico al que se le ha privado de una continuidad artística habitual como sugiere Marcus (2013: 23), y que no ha podido, hasta el final de su vida, conocer, asimilar y evolucionar como autor ante la respuesta de su público: "Los mejores artistas populares crean vínculos inmediatos entre personas que no tienen en común más que la respuesta a su trabajo, pero los mejores artistas populares jamás cesan de intentar comprender el impacto de su trabajo en el público".

Finalmente, el contexto histórico del documental, la institución de la música de Rodríguez como bandera de una revolución social en Sudáfrica, gracias a que, como indica Morne (citado por Nussbaum 2012: 1), "usted no podría haber diseñado una mejor audiencia para Rodríguez que la juventud Afrikaans durante los años setenta y ochenta.", convierten a esta obra en una pieza única rockymentary de los últimos años; debido a, principalmente, tres pilares fundamentales: la presencia de un autor maldito, la recompensa final e inesperada para el reconocimiento público de su obra, y el formato de investigación que articula toda la historia narrativa de Malik Benjelloul.

\section{BIBLIOGRAFÍA}

ABEILLÉ, Constanza, "Modos de representar la realidad: Aproximaciones teóricas al Rockumental", Revista Toma Uno, n 1, 2012, pp. 55-66.

FRAGO, Marta (2008), "Del negro al gris: Howard Hawks en la adaptación de The Big Sleep", Zer, vol. $13, n^{\circ} 24,2008$, pp. 257-279.

MARCUS, Greil, Mistery Train. Imágenes de América en la música rock \& roll, Barcelona, Contra, 2013.

NICHOLS, Bill, La representación de la realidad. Cuestiones y conceptos sobre el documental. Barcelona, Paidós, 1997.

NUSSBAUM, Barbara, "Sugar Man, Afrikaners' musical healer and voice", Cape Times, 27/02/2013. http://www.iol.co.za/capetimes/sugar-man-afrikaners-musical-healer-1.1478019 (acceso 10/04/2014).

RUEDA, Natalia, "El documental musical y la audiovisualización de estéticas marginales", Revista Comunicación, vol.1, n 10, 2012, pp. 1172 - 1182.

SULLÀ, Enric, "Sobre la formación del canon del cine negro", Revista electrónica de teoría de la literatura y literatura comparada, 3, 2010, pp. 13-28.

GÓMEZ TARÍN, Francisco Javier, El análisis del texto filmico, Castellón, Universitat Jaume I, 2006. VOGLER, CHRISTOPHER, El viaje del escritor, Barcelona, Robinbook, 2002. 
WOOLGAR, STEVE (ed.), ¿Sociedad virtual? Tecnología, 'cibérbole', realidad, Barcelona, Editorial UOC, 2005.

\section{Films citatados}

20 Feet from Stardom (Morgan Neville, 2013)

Big Easy Express (Emmett Malloy, 2012)

Elvis on Tour (Robert Abel, Pierre Adidge, 1972)

George Harrison: Living in the Material World (Martin Scorsese, 2011)

Gimme Shelter (Albert y David Maysles, Charlotte Zwerin, 1970)

No Direction Home: Bob Dylan (Martin Scorsese, 2005)

Shine a Light (Martin Scorsese, 2008)

The Last Waltz (Martin Scorsese, 1978),

The Filth and the Fury (Julien Temple, 2001)

When You're Strange (Tom DiCillo, 2009)

What's Happening! The Beatles in America (Albert y David Maysles, 1964)

Woodstock: 3 Days of Peace \& Music (Michael Wadleigh, 1970)

Year of the Horse (Jim Jarmusch, 1997) 
